\title{
Design, Optimization, Development of a New RP-HPLC Method For Simultaneous Estimation of Thiocolchicoside and Diclofenac in Bulk and Tablet Formulations
}

\author{
B. Sowjanya and K. Rambabu \\ Department of Chemistry, $R V R$ \& $J$ C College of Engineering, \\ Chowdavaram, Guntur, Andhra Pradesh, India \\ Corresponding author email: Soujanya_3333@yahoo.co.in
}

\section{ABSTRACT}

A reversed-phase high performance liquid chromatography technique has been effectively designed, produced for the concurrent assurance of thiocolchicoside and diclofenac in a medication detailing. The RP-HPLC strategy utilized a Phenomenex C18 reversed phase column (Luna $5 \mu, 250 \times 4.6 \mathrm{~mm}$ ) with an isocratic combination of methanol Ammonium acetic acid buffer (pH:4.2), acetonitrile and methanol in the proportion 40:40:20 \%v/v as the versatile phase. The column temperature was kept at $30{ }^{\circ} \mathrm{C}$. The stream rate was $1.0 \mathrm{~mL} / \mathrm{min}$ and discovery was through an UV finder at frequency of $263 \mathrm{~nm}$. Every one of the dynamic segments was effectively eluted with mean maintenance seasons of 2.833and 4.263min for thiocolchicoside and diclofenac separately. The strategy was discovered to be direct (R2 $>0.99$ ), exact (RSD $<2.0$ \%), precise (recuperations 99.8.9-100.9 \%), explicit, straightforward, delicate, fast and vigorous. The approved technique can be utilized in routine quality control investigation of fixed portion blend tablets.

KEY WORDS: RP-HPLC, THIOCOLCHICOSIDE, DICLOFENAC AND METHOD DEVELOPMENT.

\section{INTRODUCTION}

Thiocolchicoside (Kamath, A.. 2013; Pedro, GB., et al., 2009; Trellua M, et al., 2004; Janbroers, JM.,1987) (Figure 1), (s)-N-[3-(B-D-gluco pyrano xyloxy)-5, 6, 7, 9-tetrahydro-1, 2- dimethoxy-10-(methylthi o)-9-oxobenzo (a) heptalen-7yl] acetamide, is a muscle relaxant employed in the symptomatic treatment of painful muscle spasms.

Diclofenac Sodium (Indian Pharmacopoeia,2010; The United State pharmacopoeia, 2005; Chlao CSL and Robinson JR., 1995; Hardman, JG., et al.,2001) (Figure 2), is a non-steroidal quieting drug (NSAID) taken to reduce irritation and a torment easing, lessening distress in conditions like joint aggravation or extraordinary injury. The blend of thiocolchicoside and diclofenac for oral use in treating rheumatic joint aggravation osteoarthritis,

Biosc Biotech Res Comm P-ISSN: 0974-6455 E-ISSN: 2321-4007

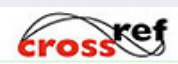

Identifiers and Pagination

Year: 2021 Vol: 14 No (9) Special Issue

Pages: $285-290$

This is an open access article under Creative

Commons License Attribn 4.0 Intl (CC-BY).
DOI: http://dx.doi.org/10.21786/bbrc/14.9.53

Commons License Attribn 4.0 Intl (CC-BY).
DOI: $h t t p: / / d x . d o i . o r g / 10.21786 / b b r c / 14.9 .53$ musculoskeletal injuries and continuous torture related with sickness. Composing outline uncovered a couple of logical methods (Rajan,V.Rele.,2016; Samanthula,G., et al., 2014;A.R.Umarkar,AR., et al., 2011;Deshpande, S., et al., 2014 Jadhav, SD., ,2015; Satyanarayana, MV., 2014) for the examination of thiocolchicoside and diclofenac in blends represented. Till today no details were established for affirmation of thiocolchicoside and diclofenac by RPHPLC process in predetermined mix.

Figure 1.Thiocolchicoside composition

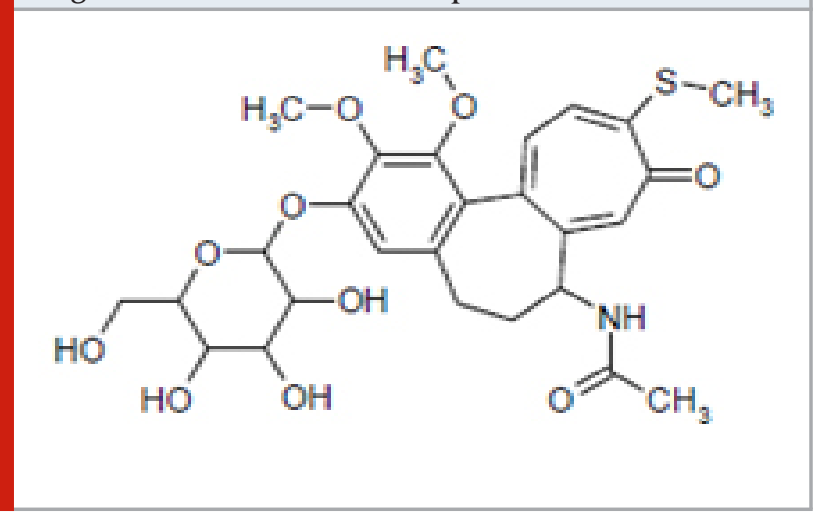

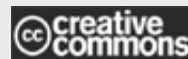

Article Information

Received: $19^{\text {th }}$ Apr 2021

ccepted after revision: $30^{\text {th }}$ June 2021 
Figure 2.Diclofenac configuration

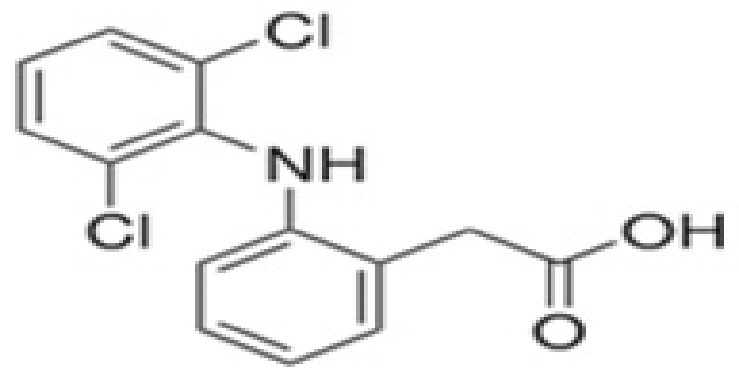

Experimental

a. Instrumentation: The chromatographic method executed on a Shimadzu LC20-AT Liquid chromatography with SPD-20A conspicuousness UV-noticeable locator and Spinchrom programming, turned around phase C18 column (Phenomenex 5, $250 \mathrm{~mm} \times 4.6 \mathrm{~mm}$ ) as fixed phase. Thermo electron partnership twofold shaft UV-obvious spectrophotometer (vision favorable to programming),Ultrasonic cleaner, Shimadzu logical equilibrium AY- 220,Vaccum miniature filtration unit with $0.45 \mu$ film channel be utilized inthe examination.

b. Reagents and Chemicals: Pharmaceutically unadulterated sample of thiocolchicoside and diclofenac, were acquired as blessing samples from Chandra Labs, Prashanthinagar, Kukatpally, and Hyderabad, India. The immaculateness of these medications was assessed by acquiring its softening point and bright (UV) and infrared (IR) spectra and was utilized minus any additional filtration. Acetonitrile, Methanol and water of HPLC grade was gotten from merck substance division, mumbai and ammonium acetic acid derivation (AR-grade) and orthophosphoric acid (GR grade) was acquired from qualigens ltd., mumbai. Every one of the weakenings in the current measure were performed with standard class-A, volumetric flasks. Tablet definition in the brand name of Thioquest-D Capsues (Alkem Labs) name guarantee; thiocolchicoside $5.0 \mathrm{mg}$ and diclofenac $50 \mathrm{mg}$ for oral utilization was acquired from the neighborhood pharmacy.

c. Mobile Phase: Prepared a degassed combination of Ammonium acetic acid buffer(pH:4.2), acetonitrile and methanol in the proportion 40:40:20 \%v/v separately. Buffer Preparation: Weigh precisely about $3.85 \mathrm{gms}$ of Ammonium acetic acid derivation made up with $200 \mathrm{ml}$ of HPLC Grade water and lastly to $1000 \mathrm{ml}$ with HPLC grade water. The at that point change the $\mathrm{pH}: 4.2$ with Orthophosphoric acid and sifted through a $0.45 \mu$ film channel.

d. Standard Solutions: Standard stock arrangements of thiocolchicoside $(50 \mu \mathrm{g} / \mathrm{mL})$ and diclofenac $(500 \mu \mathrm{g} / \mathrm{mL})$ were set up by dissolving 5.0mg and 50mg in two $100 \mathrm{~mL}$ volumetric flasks at first containing $10 \mathrm{ml}$ of mobile phase separately. Afterward, the volumes were made sufficient by means of mobile phase to acquire stock concentrations of $50 \mu \mathrm{g} / \mathrm{mL}$ and $500 \mu \mathrm{g} / \mathrm{mL}$. From the above stock arrangements, aliquots of every arrangement were pipetted into a progression of $100 \mathrm{mLvolumetric}$ flasks containing $25 \mathrm{~mL}$ ofthe mobile phase and made sufficient with diluent to get a last centralization of 5.0 - $15 \mu \mathrm{g} / \mathrm{mL}$ and $50-150 \mu \mathrm{g} / \mathrm{mL}$ for thiocolchicoside and diclofenac individually.

e. Sample Solutions: Weighed and finely powdered 10 Thioquest-D Capsues (A1chem restricted) [label guarantee; thiocolchicoside 5.0mg and diclofenac 50mg] was obtained from the neighborhood pharmacy. Precisely gauge and move the grounded powder comparable to $5.0 \mathrm{mg}$ of thiocolchicoside and $50 \mathrm{mg}$ of diclofenac into a $100 \mathrm{~mL}$ volumetric flagon, added $70 \mathrm{~mL}$ of diluent, and sonicated for 30minutes with irregular trembling at controlled temperature and weakened to volume by diluent and blended altogether. Sifted the arrangement through $0.45 \mu \mathrm{m}$ film channel. Move aliquots of the above arrangement into a progression of $25 \mathrm{~mL}$ volumetric flask and weakened to volume by diluent to get a centralization of thiocolchicoside and diclofenac that comply inside the standard fixation restricts individually.

\section{RESULTS AND DISCUSSION}

i. Method Development: In building up the proposed method different streamlining considers were completed, basing on the synthetic idea of the above referred to drugs. First and foremost the assurance of working frequency $(\lambda \max )$ was made in the current examination. For this $5.0 \mathrm{mg}$ of the thiocolchicoside and diclofenac drug were taken in various $10 \mathrm{ml}$ volumetric jar and broke down in methanol and volume made sufficient. The above arranged arrangements be checked in the UV range amid 200-400nm utilizing methanol as clear. From the above investigations the isosbestic point for thiocolchicoside and diclofenac were discovered to be $263 \mathrm{~nm}$ and this frequency was chosen as the recognition frequency for the above referred to drugs in the current test.

Figure 3: HPLC chromatogram of thiocolchicoside $\&$ diclofenac

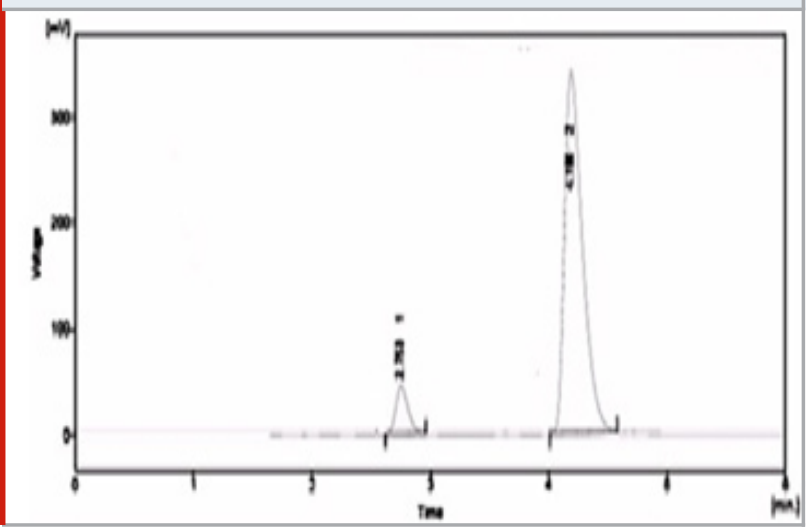

Besides preliminaries on utilizing diverse creation of the above said mobile phase [Ammonium acetic acid buffer (pH:4.2), Acetonitrile and Methanol in the proportion $45: 45: 10 \% \mathrm{v} / \mathrm{v}, 50: 30: 20 \% \mathrm{v} / \mathrm{v}$ and $40: 40: 20 \% \mathrm{v} / \mathrm{v}]$ 
were conveyed to acquire best detachment for the present chosen drugs. From these investigations it was deduced that ammonium acetic acid derivation buffer (pH:4.2), Acetonitrile and Methanol inthe proportion of 40:40:20\% $/ \mathrm{v}$ was chosen as a the best mobile phase as it brought about brilliant elution of the chose drugs with sharp and all around settled peaks and additionally with low maintenance and run times. The column choice in the current test has been done based on back pressure, goal, peak shape, hypothetical plates and everyday reproducibility of the maintenance time and goal amid thiocolchicoside and diclofenac peaks (Figure 3).

Subsequent to assessing every one of these components, Phenomenex, C-18 column $(250 \mathrm{~mm} \times 4.6 \mathrm{~mm}, 5 \mu \mathrm{m})$ was discovered to be reasonable as it gave good outcomes.
During these investigations the infusion volume and the stream pace of the mobile phase were made at $20 \mu \mathrm{L}$ and $1.0 \mathrm{~mL}$.min-1 separately.

ii. Method Legalization: The created RP-HPLC method is approved as per ICH rules (ICH.,2005) for the synchronous examine of thiocolchicoside and diclofenac utilizing the accompanying boundaries.

a. System Suitability: For framework reasonableness, six repeats of standard sample were infused and examined the boundaries like plate number $(\mathrm{N})$, following element $(\mathrm{k})$, goal (R) and relative maintenance time $(\alpha)$, HETP, limit factor (kI), plates per meter and peak evenness of samples. The aftereffects of this investigation were inside the ICH standards (Table 1).

\begin{tabular}{|c|c|c|c|c|}
\hline Compound & $\begin{array}{l}\text { Retention } \\
\text { Time }\end{array}$ & $\begin{array}{l}\text { Tailing } \\
\text { factor }\end{array}$ & $\begin{array}{c}\text { Theoretical } \\
\text { plates }\end{array}$ & $\begin{array}{c}\text { USP } \\
\text { Resolution }\end{array}$ \\
\hline Thiocolchicoside & 2.833 & 1.44 & 3267 & - \\
\hline Diclofenac & 4.263 & 1.36 & 3525 & 5.940 \\
\hline
\end{tabular}

b. Specificity: Specificity was set up by infusing dluent and fake treatment arrangements into the previously mentioned chromatographic framework utilizing the beyond chromatographic provisions and the clear and fake treatment chromatograms be documented. Chromatograms of clear and fake treatment arrangements illustrated no peaks at the maintenance season of thiocolchicoside and diclofenac peaks demonstrating with the aim of the diluent and the blank treatment utilized in the standard and sample readiness didn't meddled in the assessment of thiocolchicoside and diclofenac individually.

c. Linearity: Standard arrangements of thiocolchicoside and diclofenac at various working fixations [5.0-15 $\mu \mathrm{g} /$ $\mathrm{ml}$ for thiocolchicoside and, $50-150 \mu \mathrm{g} / \mathrm{ml}$ diclofenac] were readied and $20 \mu \mathrm{L}$ of the above standard medication arrangements were infused with the mobile phase under the chromatographic clauses depicted above at encompassing temperature and their individual chromatograms were recorded.Calibration bends were developed by plotting the convergence of portrayed medications as opposed to comparing peak areas acquired at 240nm (Figures $4 \mathrm{CH}$ ). The outcomes showed a superb connection among's

absorbance and focus level of medication inside the fixation range thiocolchicoside and diclofenac uncovering linearity that is addressed by a direct relapse condition as follows and their outcomes are given in Table 2. $\mathrm{Y}$ (Thiocolchicoside) $=18.81 \mathrm{x}+42.60\left[\mathrm{R}^{2}\right.$ $=0.9995], \mathrm{Y}$ (Diclofenac) $=34.60 \mathrm{x}-40.20\left[\mathrm{R}^{2}=\right.$ 0.9959] From these outcomes it was uncovered that the relationship coefficients for the above said drugs were more noteworthy than 0.999 and were inside the acknowledgment models there uncovering the great linearity of the proposed RP-HPLC technique.

Figure 4: Calibration curve for thiocolchicoside

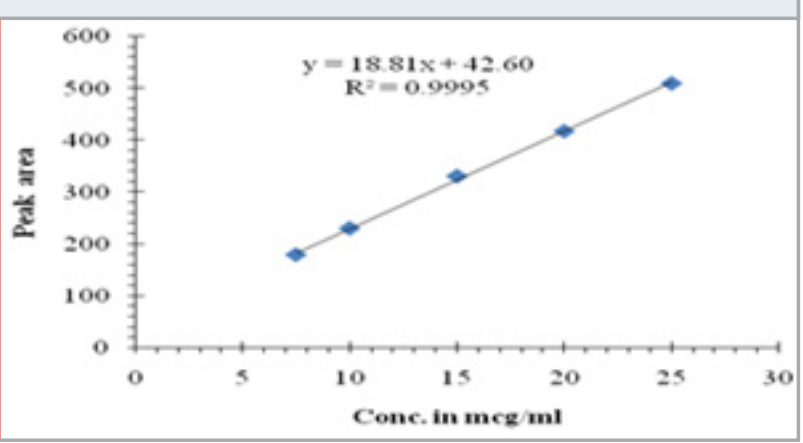

Figure 5: Calibration curve for diclofenac

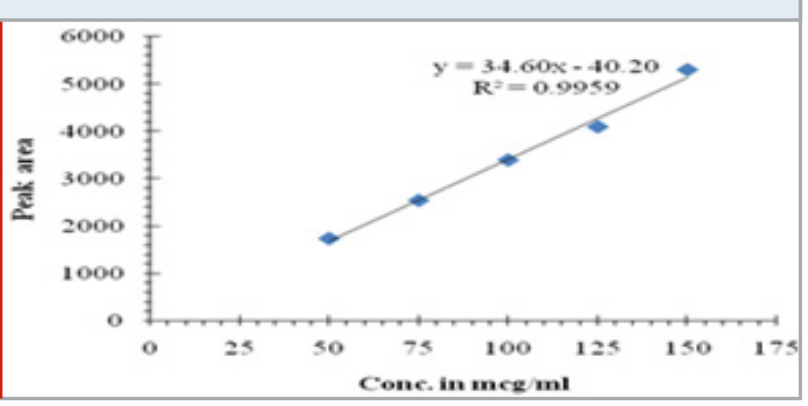

d. LOD and LOQ: The LOD and LOQ values were 0.011 and $0.038 \mu \mathrm{g} / \mathrm{ml}$ for thiocolchicoside and 0.029 and $0.099 \mu \mathrm{g} / \mathrm{ml}$ for diclofenac, revealing good sensitivity of the proposed method respectively. 
e. Precision: Exactitude of the present RP-HPLC process is judged via six reproduce insertions of 100\% test and the results were expressed in terms of standard deviation and $\%$ RSD. The $\%$ RSD values of method precision were found to be 0.502 for thiocolchicoside and for diclofenac 0.507 for respectively and these results indicated that the current RP-HPLC method was highly precise. The method precision results were specified within Table 3 respectively. f. Accuracy:Identified measures of standard arrangements thiocolchicoside and diclofenac be adjoined by $10 \%$ focus to pre evaluated sample arrangements of thiocolchicoside $(5.0,10,15.0 \mu \mathrm{g} / \mathrm{ml})$, and diclofenac $(50,100,150 \mu \mathrm{g} /$ $\mathrm{ml})$. The measure of thiocolchicoside and diclofenac recuperated was determined and the outcomes were summed up in Table 4. From the outcomes the $\%$ recuperation esteems for thiocolchicoside and diclofenac were gone from 99.75-100.9\% and 100.1-100.6\% separately making the proposed strategy precise.

Table 2. Linearity Studies

\begin{tabular}{|c|c|c|c|c|}
\hline \multicolumn{3}{|c|}{ Thiocolchicoside } & \multicolumn{2}{c|}{ Diclofenac } \\
\hline$\%$ Level & Conc. $\mu \mathrm{g} / \mathrm{mL}$ & Area & Conc. $\mu \mathrm{g} / \mathrm{mL}$ & Area \\
\hline 50 & 7.5 & 179.857 & 50 & 1749.894 \\
\hline 75 & 10 & 231.025 & 75 & 2550.984 \\
\hline 10.0 & 15 & 331.489 & 100 & 3401.012 \\
\hline 12 & 20 & 418.244 & 125 & 4100.687 \\
\hline $150 \quad 25$ & 510.546 & 150 & 5300.248 \\
\hline \multicolumn{2}{|c|}{ Slope } & 18.81 & Slope & 34.60 \\
\hline Intercept & 42.6 & Intercept & -40.20 \\
\hline RSQ $(\mathrm{r} 2)$ & 0.9995 & RSQ $(\mathrm{r} 2)$ & 0.9959 \\
\hline \multicolumn{2}{|c|}{ LOD $(\mathrm{mcg} / \mathrm{ml})$} & 0.011 & LOD $(\mathrm{mcg} / \mathrm{ml})$ & 0.029 \\
\hline \multicolumn{2}{|c|}{ LOQ $(\mathrm{mcg} / \mathrm{ml})$} & 0.038 & LOQ $(\mathrm{mcg} / \mathrm{ml})$ & 0.099 \\
\hline
\end{tabular}

Table 3. Technique Exactitude

\begin{tabular}{|c|c|c|c|}
\hline \multicolumn{2}{|c|}{ Thiocolchicoside } & \multicolumn{2}{c|}{ Diclofenac } \\
\hline $\begin{array}{c}\text { Technique Exactitude (Inter \&Intra } \\
\text { Day) }\end{array}$ & 100.2 & 99.4 & 99.99 \\
\hline 100.1 & 100.4 & 99.7 & 100.1 \\
\hline 100.7 & 99.68 & 98.7 & 98.89 \\
\hline 99.47 & 99.75 & 98.7 & 99.08 \\
\hline 99.39 & 99.57 & 98.6 & 99.07 \\
\hline 99.28 & 99.69 & 99.2 & 99.28 \\
\hline 100.5 & 99.98 & & 99.25 \\
\hline Overall Avg. & 0.514 & & 0.497 \\
\hline Overage Std Dev. & 0.502 & & 0.507 \\
\hline Over all \%RSD & & & \\
\hline
\end{tabular}

Table 4. Recuperation Studies

\begin{tabular}{|c|c|c|}
\hline \multicolumn{3}{|c|}{ Thiocolchicoside } \\
\hline \% Level & Recovery Range & $\%$ RSD \\
\hline 50 & 100.6-100.9 & 0.1 \\
\hline 100 & $99.3-100.0$ & 0.4 \\
\hline 150 & $99.7-99.8$ & 0.1 \\
\hline \multicolumn{3}{|c|}{ Diclofenac } \\
\hline \% Level & Recovery Range & $\%$ RSD \\
\hline 50 & $100.2-100.5$ & 0.1 \\
\hline 100 & $100.1-100.6$ & 0.3 \\
\hline 150 & $100.3-100.5$ & 0.1 \\
\hline
\end{tabular}

g. Sturdiness: Vigorness of the current proposed method was done by altering the experimental surroundings that include (i) effect of alter in flow rate $(1.0)_{ \pm 0.2 \mathrm{~mL}} / \mathrm{min}$ and (ii) effect of detection wavelength(263nm) varied by \pm 2 .0nm. The consequences of vigor investigation of the proposed strategy are introduced in Table 5 and these outcomes showed that the measure estimation of the test readiness arrangement was somewhat influenced and was as per that of genuine during the above said fluctuation conditions. And more over the system suitability parameters were also found satisfactory concluding the developed method as robust.

h. Analysis of pharmaceutical formulations: Analysis of marketed tablets (Thioquest-D; Label claim- Capsules (A1chem limited) [label claim; thiocolchicoside 5.0mg and diclofenac 50mg] was done utilizing the above said upgraded mobile phase and HPLC conditions. The \% drug substance of tablets got by the projected technique pro thiocolchicoside and diclofenac be 
discovered designated 99.43 and 99.97\% individually. These outcomes uncovered that the assessment of the present chosen drugs in their measurement structures was precise inside the acknowledgment level. The outcomes are given in Table 6 .

Table 5. Robustness studies

\begin{tabular}{|c|c|c|c|}
\hline \multirow{2}{*}{ Constraint } & \multicolumn{2}{|c|}{ \% RSD } & \%RSD \\
\cline { 2 - 4 } & \multicolumn{2}{|c|}{ Thiocolchicoside } & Diclofenac \\
\hline \multirow{3}{*}{ Wavelength $\pm 2.0 \mathrm{~nm}$} & $261 \mathrm{~nm}$ & 0.35 & 0.38 \\
\cline { 2 - 4 } & $265 \mathrm{~nm}$ & 0.45 & 0.67 \\
\hline \multirow{3}{*}{ Flow Rate $\mathrm{mL} / \mathrm{min}$} & $0.8 \mathrm{~mL} / \mathrm{min}$ & 0.24 & 0.31 \\
\cline { 2 - 4 } & $1.2 \mathrm{~mL} \cdot \mathrm{min}$ & 0.64 & 0.75 \\
\hline
\end{tabular}

Table 6. Outcomes in formulations

\begin{tabular}{|l|c|c|c|}
\hline $\begin{array}{l}\text { Brand } \\
\text { (Thioquest-D) }\end{array}$ & $\begin{array}{c}\text { Quantity assert } \\
\text { in mg per tablet }\end{array}$ & Thiocolchicoside & Diclofenac \\
\hline Thiocolchicoside & 5.0 & 4.954 & 99.43 \\
\hline Diclofenac & 50 & 49.97 & 99.97 \\
\hline
\end{tabular}

\section{CONCLUSION}

An isocratic, synchronous and HPLC technique with photodiode exhibit identification for the assessment of thiocolchicoside and diclofenac medicine has been created. The created strategy holds an adequate level of framework appropriateness, selectivity, power, exactness and precision as per worldwide rules. The chromatographic elution is done in a brief time frame $(<$ $5 \mathrm{~min}$ ) with great affectability. Consequently, the present HPLC strategy can be useful for assessing the grouping of thiocolchicoside and diclofenac medicine at the same time in tablet dose structures and mass medications in quality control research facilities.

\section{ACKNOWLEDGEMENTS}

The authors thank the administration,Department of Chemistry, R V R \& J C College of Engineering, Chowdavaram, Guntur, Andhra Pradesh for giving permission as well as providing all facilities to complete this research work. and furthermore Chandra labs, Hyderabad for giving medications.

\section{REFERENCES}

Chlao, C.S.L., Robinson, J.R.,(1995).Remingtons Pharmaceutical Sciences. Mack Publishing Company, Pennsylvania, pp.1536.

Deshpande,S.,Patel,A.R., (2014). Stability indicating simultaneous estimation of thiocolchicoside, paracetamol and diclofenac sodium in bulk drug and formulation by RP- HPLC. The World Journal of Pharmaceutical Sciences, 2(7): pp. 671-678.
Hardman, J.G., Limbird, L.E,Gillman, A.G., (2001). Goodman and Gillman's: The pharmacological basis of therapeutics. Mc. Graw Hill Medical Publishing Division, pp.709.

Indian Pharmacopoeia (2010), Government of India, The Controller of Publications, 6(3),pp.2213.

ICH.,(2005), Q2B Validation of analytical procedure: Methodology International Conference on Harmonization, Geneva.

Jadhav S.D., Butle S.R., Patil SD., Jagtap P.K., (2015). Validated stability indicating RP-HPLC method for simultaneous determination and in vitro dissolution studies of thiocolchicoside and diclofenac potassium from tablet dosage form: Arabian Journal of Chemistry, 8(1),pp.118-128.

Janbroers JM.,(1987). Review of the toxicology, pharmacodynamics and pharmacokinetics of thiocolchicoside, a GABA-agonist muscle relaxant with anti-inflammatory and analgesic actions: Acceptance and Commitment Therapy, 13,pp 221-227.

Kamath A.,(2013). Thiocolchicoside: a review. DHR International Journal of Medical Sciences, 4(2),pp.4246:

Pedro, G.B., Mara, G.B., Luciana, K.T, Luis, F.C, Antono, A.M., Jorge K., (2009). Epileptic seizure after treatment with thiocolchicoside:Therapeutics and Clinical Risk Management, 5,pp 635-637.

Rajan,V.Rele., (2016). Reverse phase high performance liquid chromatography for simultaneous determination of diclofenac and thiocolchicoside in bulk drug and pharmaceutical dosage orm, Der Pharmacia Lettre, 2016, 
8 (1):80-84.

Samanthula, G., Shrigod,V.V., Patel,P.N., (2014).Validated stability-indicating assay method for simultaneous determination of aceclofenac and thiocolchicoside using RP-HPLC: Drug Research , 64(8): pp.429-435.

Satyanarayana, M.V., Satyadev, T.N., Ganji, R., Anuradha, V., (2014). Method development and validation of stability indicating RP-HPLC method for simultaneous estimation of thiocolchicoside and diclofenac in bulk and its pharmaceutical formulations: Indo American Journal of Pharmaceutical Research, 4(3).

The United State pharmacopoeia ., (2005), 29th ed.
United States Pharmacopoeial Convention, Inc., Rockville, MD 206,pp. 683.

Trellua M., Filali-Ansary A., Francon D., Adam R., Luel PL., (2004). New metabolic and pharmacokinetic characteristics of thiocolchicoside and its active metabolite in healthy humans: Fund Clinical Pharmacy, 18,pp.493-497.

Umarkar A.R, Rewatkar N.S., Charde M.S., Charde R.M.,.KastureA.V., (2011).RP-HPLC Method Development and Validation for Estimation of Thiocolchicoside and Diclofenac Potassium in Bulk and Capsule Dosage Forms: Journal of Pharmacy Research, 4(5),pp.13071308 